\title{
Nanoparticle Seeded Pulse Electrodeposition for Preparing High Performance $\mathrm{Pt} / \mathrm{C}$ Electrocatalysts
}

\author{
Cunping Huang, ${ }^{* a}$ Christopher Bunmi Odetola, ${ }^{b}$ and Marianne Rodgers ${ }^{c}$ \\ University of Central Florida, Florida Solar Energy Center, Clearlake Road, Cocoa FL 32922
}

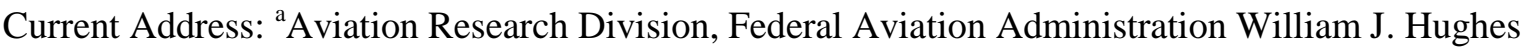

Technical Center, Atlantic City International Airport, NJ 08405, Email: cunping.huang@ faa.gov;

${ }^{b}$ Faculty of Science, University of Ontario Institute of Technology, 2000 Simcoe Street North, Oshawa, Ontario, Canada, L1H 7K4, Email: Christopher.odetola@uoit.ca; ${ }^{\mathrm{c}}$ Wind Energy Institute of Canada, 2174 Route, North Cape, Prince Edward Island, Canada C0B 2B0, marianne.rodgers@weican.ca

*Corresponding author.

\begin{abstract}
Pulse electroplating technology has been applied in the preparation of $\mathrm{Pt} / \mathrm{C}$ electrocatalysts for hydrogen fuel cell electrodes. The major challenge of this technology is the aggregation of Pt nanoparticles on the carbon support. This research reports a Pt nanoparticle seeded pulse electroplating procedure for preparing $\mathrm{Pt} / \mathrm{C}$ electrocatalysts used for oxygen reduction reaction (ORR). Pt nanoparticles were predeposited onto a carbon support as nuclei, followed by pulse electrodeposition. This new approach is able to overcome particle aggregation issues and improve catalyst performance. Preliminary results show that a prepared $0.1 \mathrm{wt} . \% \mathrm{Pt}$ loaded Pt/C electrode achieves higher performance than a commercial electrode with 0.5 wt.\% loading. Atomic level STEM analyses reveal that free Pt atom clusters exist around Pt nanoparticles severing as nuclei and promoting particles' growth evenly during electroplating. This result is verified by SEM images which indicate that the prepared Pt particles on the carbon surface are uniformly distributed and each particle is packed loosely with nanosized Pt flakes. The higher surface areas and mass transfer rates of Pt nanoflakes on the surface of Pt particles lead to higher ORR efficiency. Although a commercial $\mathrm{Pt} / \mathrm{C}$ electrode was used for comparison, this exploratory research was based on a rotational disk electrode and large scale fuel cell testing is needed to confirm the finding.
\end{abstract}

Keywords: pulse electroplating, Pt nanoparticles, electrocatalysts, hydrogen PEM fuel cell, oxygen reduction reaction

\section{Introduction}


The cost of hydrogen polymer electrolyte membrane (PEM) fuel cells is a critical factor in the hydrogen economy. About $40 \%$ of the cost of a PEM fuel cell derives from the cost of the Pt electrodes.[1] There are currently two major approaches to reducing the cost of fuel cell electrodes: (1) Development of non-Pt based electrodes and (2) Synthesis of very low Pt loaded electrodes. It has been found that the fundamental disadvantage of $\mathrm{Pt} / \mathrm{C}$ electrodes prepared by conventional methods is that not all Pt particles on the carbon supports can be utilized for electron transfer because only those located in the interface of the Nafion ${ }^{\circledR}$ membrane and the catalyst layers can be accessed by both protons and electrons. Many experimental studies have been devoted to the above two research fields and much progress has been made. [2,3] Pulse electrodeposition of Pt particles is one of the intensively investigated technologies for the synthesis of low Pt loaded electrodes.[4-6] The strategy of this technology is to deposit Pt particles onto areas of electrodes accessible to both electrons and protons during the oxygen reduction reaction (ORR: $\mathrm{O}_{2}(\mathrm{~g}) 4 \mathrm{H}^{+}+4 \mathrm{e}^{-}=\mathrm{H}_{2} \mathrm{O}$ ). Many successes have been achieved using this technology. [7-9] However, due to the non-uniformity and low hydrophilicity of the carbon surface, Pt particle aggregation occurs during electroplating and is detrimental to the improvement of the Pt catalyst. This preliminary research investigates a facile Pt nanoparticle seeded electroplating method for the preparation of low $\mathrm{Pt}$ loaded catalysts to be used as anodes for hydrogen PEM fuel cell ORR applications.

\section{Experimental}

2.1. Preparation of A Non-Catalyst Carbon Electrode: Carbon powder (XC-72, Cabot) was heated at $600^{\circ} \mathrm{C}$ under nitrogen for three hours to remove both moisture and potentially adsorbed organics. Prepared carbon powder, methanol, water, and a 5\% Nafion solution (1100 EW, Ion Powder) were mechanically stirred using an Omni GLH Homogenizer (Omni Inc.) for six hours for the preparation of an ink. The carbon electrode was created by spraying the ink onto a 10BC gas diffusion layer (SGL Carbon) with an airbrush (Badger), creating 5 to $25 \mathrm{~cm}^{2}$ non-catalyst carbon electrode pieces with $0.45 \mathrm{mg} / \mathrm{cm}^{2}$ carbon and $32 \mathrm{wt}$ \% ionomer loading. For a quick evaluation of electrode performances, a rotating disk electrode (Pine Instruments) was used for catalyst electroplating as well as for the ORR measurements. A double junction electrode ( $\mathrm{Ag} / \mathrm{AgCl}$, Pine Instruments) was used as a reference electrode to reduce possible contamination due to electrolyte discharge. Platinum gauze $\left(2 \times 2 \mathrm{~cm}^{2}\right.$, Pine Instruments $)$ served as a counter electrode and was placed as close to the working electrode as possible. The working electrode was created from a non-catalyst carbon electrode disk $(1.0 \mathrm{~cm}$ in diameter) deposited with Pt via pulse electroplating. 
2.2. Preparation of Nanosized Pt Colloidal Solution: Sodium borohydride $\left(\mathrm{NaBH}_{4}, 98 \%\right)$ and polyvinylpyrrolidone (PVP, K30, $\left.[\mathrm{MW}]_{\text {avg }}=40,000\right)$ were acquired from Acros Organics and Fluka, respectively. All chemicals were used as received, without further purification. Pt metal colloid particles were prepared by a modified method based on $\mathrm{NaBH}_{4}$ reduction of a dilute $\mathrm{H}_{2} \mathrm{Pt}(\mathrm{IV}) \mathrm{Cl}_{6}$ solution. In detail, a freshly prepared $\mathrm{NaBH}_{4}$ solution $(0.20 \mathrm{mg}$ in $10 \mathrm{~mL}$ deionized water) was drop wisely added, under vigorous stirring, to a $15 \mathrm{~mL}$ aqueous solution containing $1.00 \mathrm{mM} \mathrm{H}_{2} \mathrm{Pt}(\mathrm{IV}) \mathrm{Cl}_{6}$. In order to prevent aggregation of $\mathrm{Pt}$ nanoparticles during $\mathrm{Pt}(\mathrm{IV})$ ion reduction a small amount of a water soluble polymer, PVP, was added to the solution and mixed thoroughly with $\mathrm{H}_{2} \mathrm{Pt}(\mathrm{IV}) \mathrm{Cl}_{6}$ prior to the reduction. The preparation took place under room conditions and the resulting colloidal Pt nanoparticles were used as nuclei for the modification of carbon electrodes before pulse electroplating.

2.3. Preparation of Pt Nanoparticle Seeded Carbon Electrodes: Before electroplating, non-catalyzed carbon electrode disks were dried in a vial for 30 minutes at $70^{\circ} \mathrm{C}$. After drying, the samples were weighed in a glove box under a nitrogen atmosphere to preclude a humidity affect. Modification of the carbon electrode disks was carried out by placing them on the surface of the aqueous Pt colloidal solution diluted with deionized water at a 1:1 ratio. The process was carried out under sonication at room temperature for 30 minutes. After soaking, the samples were dried for 30 minutes at $70^{\circ} \mathrm{C}$. The soaking and drying procedures were repeated either five times or eight times for a given sample, after which the samples were carefully weighed in the same glove box to determine the loaded weight of the modified electrodes. In this experiment the weight gain of the Pt modification was minimal. It could not be determined by comparing weightsbefore and after modification because the Pt nanoparticle concentration was too dilute and the nanoparticles deposit only onto the surfaces of the carbon electrodes. Other instrumental analyses would be required to determine the very low level of Pt loading at this stage. Additionally, the modification process is not optimized and more research is needed to address the number of Pt nanoparticle seeds and the concentration of Pt colloidal solution needed for electroplating.

2.4. Pulse Electrodeposition of the Pt Catalyst: Carbon electrodes were placed into an in-house made sample holder on the tip of a rotating disk electrode. The rotating disk electrode, along with the counter electrode, a reference electrode and a gas supply inlet were placed into a $50 \mathrm{~mL}$ four-necked flask containing 0.5 $\mathrm{M} \mathrm{H}_{2} \mathrm{SO}_{4}$ (Fisher Scientific). The flask was placed into an isothermal water bath $\left(25^{\circ} \mathrm{C}\right)$. For each experiment, the electrolyte was purged with ultra-high purity argon for at least 20 minutes to eliminate dissolved $\mathrm{O}_{2}$ prior to electroplating. The pulse electroplating consisted of two steps: (1) a cyclic voltammogram scanning (CV) and (2) pulse electrodeposition. A CV was carried out using a Princeton Applied Research 2273 potentiostat with scanning voltages from - 0.2 to $1.1 \mathrm{~V}$ (vs. NHE) at a scan rate of 
$100 \mathrm{mV} / \mathrm{s}$ and $1600 \mathrm{rpm}$ for the working electrode, until the last two CV spectra overlapped. The purpose of CV scanning was (1) to remove adsorbed impurities from the carbon surface and (2) to get a stable carbon surface for starting electroplating. After CV scanning the carbon electrode was washed with deionized water (Millipore) and a $25 \mathrm{~mL}$ electrolyte containing $2.5 \mathrm{mM} \mathrm{H}_{2} \mathrm{Pt}(\mathrm{IV}) \mathrm{Cl}_{6}(99.9+\%$, Sigma Aldrich). 0.5 $\mathrm{M} \mathrm{H}_{2} \mathrm{SO}_{4}$ was added to the flask. A small amount of isopropanol (ACS grade from Fisher) was added to the electrolyte to reduce Pt particle size. Prior to electroplating the solution was purged with argon gas for at least 15 minutes to remove dissolved $\mathrm{O}_{2}$. The rotation rate of the working electrode was set to $400 \mathrm{rpm}$ and pulse electrodeposition was carried out at $25^{\circ} \mathrm{C}$ with 50 and $400 \mathrm{~mA} / \mathrm{cm}^{2}$ peak current $25 \mathrm{~ms}$ on-time and $50 \mathrm{~ms}$ off-time. These pulsating parameters were optimal conditions, determined via a series of pre-testing runs. After electrodeposition the electrode was washed several times with deionized water.

2.5. Evaluation of Prepared Electrodes: The electroplated electrodes were placed in a $0.5 \mathrm{M} \mathrm{H}_{2} \mathrm{SO}_{4}$ solution that was purged with argon for over 20 minutes at $25^{\circ} \mathrm{C}$ before each experimental run. A similar surface CV cleaning process was carried out at voltages from -0.1 to $0.9 \mathrm{~V}$ (vs. NHE) with a $100 \mathrm{mV} / \mathrm{s}$ scanning rate and a $1600 \mathrm{rpm}$ of working electrode. Three or four CV scans were performed until the last two CV curves overlapped, establishing a starting point for ORR performance measurements. The electrolyte ( $25 \mathrm{~mL}$ of $0.5 \mathrm{M} \mathrm{H}_{2} \mathrm{SO}_{4}$ ) was then purged with $\mathrm{O}_{2}$ (ultra-high purity) for at least 15 minutes. The ORR activity measurements were carried out from 0.1 to $0.9 \mathrm{~V}$ (vs. NHE) at a scanning rate of 5 $\mathrm{mV} / \mathrm{s}$ and at $1600 \mathrm{rpm}$. After ORR the sample disks were washed using DI water and were then dried for 30 minutes at $70^{\circ} \mathrm{C}$. The sample weights were taken in the glove box with reduced humidity level. The mass differences, before and after Pt electroplating, were used to calculate the Pt loading. To establish a baseline standard, one commercial electrode, $\mathrm{Pt} / \mathrm{C}$ with $0.5 \mathrm{mg} / \mathrm{cm}^{2} \mathrm{Pt}$ loading, was also evaluated for its ORR performance under identical conditions.

2.6. Electron Microscopy Analyses: The scanning electron microscopy (SEM) was carried out using a Zeiss ULTRA-55 FEG scanning electron microscope. The atomic level analyses were performed using JEOL JEMARM200F. In these analyses, the imaging probe size was $8 \mathrm{c}$. All the images were taken in a High Angle Annular Dark Field (HAADF) mode so that the intensities of the contrast were related to atomic numbers. Pt particles were also examined by thermal or cold emission guns. A $1.3 \AA$ diameter electron probe was used for the detection of single Pt atoms.

\section{Results and Discussion}

\subsection{ORR Polarization Curves of Commercial Catalyst}


This conceptual research used the rotating disk electrode method for expedient and less costly evaluation of hydrogen PEM fuel cell electrocatalysts. ORR performance of a commercial catalyst, $\mathrm{Pt} / \mathrm{C}(0.5$ $\mathrm{mg} / \mathrm{cm}^{2}$ ) was established as baseline under identical conditions. Future verification of the results should be carried out using larger electrodes based on fuel cells.

Fig. 1 shows a typical polarization curve and cell power density of the commercial catalyst obtained via a rotating disk electrode. The polarization curve features three typical stages of polarization losses: kinetic losses, ohmic losses and mass transport losses. The maximum cell power density is $12.79 \mathrm{~mW} / \mathrm{cm}^{2}$ at a current density of $27.0 \mathrm{~mA} / \mathrm{cm}^{2}$ and $0.474 \mathrm{~V}$ cell voltage (vs. NHE). Note that the results derived from the rotating disk electrode are highly repeatable. In this research, the ORR performances of prepared electrocatalysts were evaluated against this baseline experiment.

\subsection{ORR Performances of Electroplating on Non-Seeded Electrodes}

Fig. S1 (in the Supplementary Data of this paper) illustrates ORR polarization curves for electroplating on non-seeded electrodes. Overall, the performance of the Pt/C catalyst increases with an increase of electroplating cycles (increasing Pt loading). Experimental results indicate that 100 plating cycles under the specified plating conditions corresponds to about $0.10 \mathrm{mg} / \mathrm{cm}^{2} \mathrm{Pt}$ loading. After 300 electroplating cycles the rate of increase in performance slows down with additional plating cycles. In comparison with the commercial Pt/C electrode (Fig. 1) the prepared electrodes have lower ohmic losses in the low current density range $\left(<23 \mathrm{~mA} / \mathrm{cm}^{2}\right)$, but higher mass transport losses in the higher cell current density range (> $23 \mathrm{~mA} / \mathrm{cm}^{2}$ ). Increasing the plating cycles to 500, the cell performance at a higher cell current density is still less than that of the commercial catalyst. It appears that no matter how many plating cycles are executed, the performance of the plated $\mathrm{Pt} / \mathrm{C}$ non-seeded electrodes at higher current density is unable to match that of the commercial electrode. This characteristic, as revealed by SEM image (Fig. 10), is due toPt particle aggregation on the non-seeded carbon surface, which limits the benefits of electroplating technology. Changing pulse plating parameters, such as on-times or off-times, may overcome, to some degree, this inherent Pt particle aggregation issue, but to significantly overcome this obstacle requires a new approach.

The electrode performance can also be evaluated based on cell power density. Fig. 2 depicts cell power density as a function of cell current density for electroplated $\mathrm{Pt} / \mathrm{C}$ electrodes. When cell current density is less than $28.5 \mathrm{~mA} / \mathrm{cm}^{2}$, the electrode with 500 plating cycles shows higher power densities than those of 
the $\mathrm{Pt} / \mathrm{C}$ commercial catalyst. However, when cell current density is greater than $28.5 \mathrm{~mA} / \mathrm{cm}^{2}$ the commercial electrode exhibits higher power densities. Table 1 summarizes maximum power densities and associated cell current densities and cell voltages for prepared electrodes. Compared to a plain carbon electrode, after 100 plating cycles an electroplated electrode shows significant cell power density improvement, with the maximum cell power density increasing from 5.34 to $12.36 \mathrm{~mW} / \mathrm{cm}^{2}$ (a $131.5 \%$ increase) after 100 electroplating cycles. However, when the plating cycles were increased from 300 to 500 , the maximum cell power density increased by only $4.2 \%$ (from 13.57 to $14.14 \mathrm{~mW} / \mathrm{cm}^{2}$ ). This result further suggests that a higher number of electroplating cycles (or increasing the Pt loading) cannot significantly improve cell performance because of the Pt particles aggregated on the surface of the carbon electrodes.

\subsection{ORR Performances of Pt Nanoparticle Seeded Electrodes}

As shown in Fig. 3 and Fig. S2, after five Pt nanoparticle seedings a carbon electrode shows a significant performance increase. Table 1 shows the enhancement of maximum cell power density with each increase of seeding numbers. After eight times the maximum power density of the cell increases to $7.64 \mathrm{~mW} / \mathrm{cm}^{2}$, but this is still much lower than that of the $\mathrm{Pt} / \mathrm{C}$ commercial electrode. For example, the maximum power density increases $28.09 \%$ after five modifications, with an average of 5.62\% increase per seeding process. The percentage increase for eight modifications is $43.07 \%$, but the average increment drops to $5.38 \%$ increase per process. If comparing maximum cell power densities of electrodes modified five times and eight times , the power density increases from 6.84 to $7.64 \mathrm{~mA} / \mathrm{cm}^{2}$, a percentage increase of $11.70 \%$ and an average $3.90 \%$ per modification. These results suggest that with increasing numbers of modifications the effect of cell power density becomes gradually less significant. Very careful weight measurements show that Pt loading during the Pt nanoparticle pre-deposition process is at a minimal level and almost negligible after eight modifications. However, the improvements in performance (Fig. 3) of the modified electrodes are noteworthy because, although small, all Pt nanoparticles are deposited onto the surface of carbon supports. By comparison, the electrode performances of seeded electrodes are still far lower than that of the commercial Pt/C electrode. This could indicate that Pt density on the seeded electrodes is at a very low level. For accurate Pt loading quantative analyses are needed.

\subsection{ORR Performance of Pulse Electroplating on Seeded Carbon Electrodes}

Fig. S3 depicts the ORR performances of $\mathrm{Pt} / \mathrm{C}$ electrodes prepared by pulse electroplating on $\mathrm{Pt}$ nanoparticle seeded carbon electrodes (five modification times). In comparison with the ORR 
performance of electrodes electroplated on non-modified electrodes (Fig. 2), both ohmic and mass transport losses for Pt/C electroplated on modified carbon electrodes were significantly reduced. A modified electrode with 100 plating cycles shows higher performance than the commercial Pt/C electrode $\left(0.5 \mathrm{mg} / \mathrm{cm}^{2}\right)$ in the entire cell current density range. When Pt plating cycles increase to 200 , the performance of modified electrodes is significantly improved over that of the commercial electrode. Referring to Fig. 2, plating on non-modified electrodes does not achieve higher ORR performance in the higher current density range. As shown in Fig. 4 and summarized in Table 1, 100 electroplating cycles on a modified carbon electrode result in the highest cell power density of $13.61 \mathrm{~mW} / \mathrm{cm}^{2}$, higher than the maximum power density $\left(13.57 \mathrm{~mW} / \mathrm{cm}^{2}\right)$ with 300 electroplating cycles on a non-modified electrode. When a modified electrode is electroplated for 200 cycles, its ORR performance $\left(15.29 \mathrm{~mW} / \mathrm{cm}^{2}\right)$ surpasses the $14.14 \mathrm{~mW} / \mathrm{cm}^{2}$ highest cell power density for a plain carbon electrode electroplated for 500 cycles. In contrast to non-modified electrodes, which show lower performance at higher cell current densities, when electroplating cycles are more than 100 the ORR performances of modified electrodes have better performances than that of the commercial Pt/C electrode in the entire cell current density range.

An increase in the number of modifications results in further improvement of the ORR performance of the electrodes. Fig. S4 indicates that the ORR performances for electroplating on carbon electrodes with eight modifications show more significant improvement in polarization curves in comparison with the commercial electrode. As indicated in Table 1 and Fig. 5, the cell power performance after 50 plating cycles on a carbon electrode with eight modifications is greater than that of the commercial $\mathrm{Pt} / \mathrm{C}$ electrode. An electrode with 100 plating cycles can achieve $15.07 \mathrm{~mW} / \mathrm{cm}^{2}$ cell power density at 30.14 $\mathrm{mA} / \mathrm{cm}^{2}$ cell current density. In comparison to 12.36 and $13.61 \mathrm{~mW} / \mathrm{cm}^{2}$ maximum cell power densities for non-modified and five times modified electrodes, the performances of electroplating on eight times modified electrodes show considerably higher performances after the same number of plating cycles. This indicates that in order to achieve maximum cell performance, the density of Pt seeds plays an important role in the ORR performances of Pt/C electrocatalysts. As shown in SEM images, Pt nanoparticles can be dispersed uniformly on the surface of carbon electrodes, so the increase of Pt loading in the seeding process is insignificant in comparison with the electroplating Pt surface density.

\subsection{Morphologies of Pulse Electroplated Electrodes}

Fig. 6 shows high resolution STEM images of Pt nanoparticles used as seeds for carbon electrodes. As shown in Fig. S5, the average size of prepared Pt colloidal particles is $3.0 \mathrm{~nm}$ based on 154 particles 
measured. The diameters of 116 particles $(75.3 \%)$ are smaller than $3.5 \mathrm{~nm}$. Some particles are overlapping in the images but only a minimal number of particles are aggregated. The uniform distribution and well defined spherical shapes of Pt particles provide favorable seeding nuclei for electroplating. More importantly, an electron probe (1.3 $\AA$ in diameter) mounted in the STEM reveals single Pt atoms scattered around Pt nanoparticles as well as in the background of STEM images (Fig. 6). As estimated, Pt nanocrystal particles consist of about $10 \%$ non-crystalline cluster areas in nanoparticles. Under radiation of an electron beam during STEM observation, Pt nanosized colloidal particles are found rotating with single Pt atoms moving around them (Fig. 7). The single Pt atoms can be loaded into small pores or facets on the surface of a carbon electrode, increasing the number of nuclei for the formation of finer Pt particles during electroplating. The large number of pre-deposited Pt nuclei promotes the growth of finer and more uniformly distributed Pt nanoparticles, leading to the reduction of Pt loading and improved ORR performance.

When exposed to the bombardment of electron beams during atomic level analyses, prepared $\mathrm{Pt}$ nanoparticles started scattering and generating large numbers of free single Pt atoms around the parent particles (Fig. 8). This structure shows that, differing from rigid single crystals, Pt particles are the aggregation of free Pt atoms due to the protection of PVP capping agent in the Pt colloidal solution. As discussed in the above section, this type of "soft" Pt particles can be loaded into cavities of carbon surface providing excellent seeding nuclei for the electroplating of Pt catalysts. In addition to the scattering of Pt nanoparticles, limited particle aggregation is also observed. Fig. 9 shows the aggregation mechanisms of two Pt particles. Owing to the presence of PVP, those aggregated particles may be reformed or separated under stirring or sonication. Experimental results show that the prepared colloidal Pt solution can be stable for years under room conditions. Unlike Pt particle structures summarized in an excellent review [10], the new atomic analyses of Pt nanoparticles in this research can enhance our understanding of the structure of Pt colloidal particles and their seeding effect.

The SEM images of electroplated electrodes (Fig. 10 (A) and (B)) show that electroplating on a nonmodified carbon electrode can result in Pt particle aggregation. As shown in Fig. 2, more than 300 electroplating cycles are required in order for the electroplated electrodes to achieve the performance level of the commercial catalyst. Furthermore, a carbon electrode electroplated as many as 500 cycles still cannot compete with the performance level of the commercial electrode at a higher cell current density range. The SEM images of electroplating on nanoparticle-modified electrodes are shown in Fig. 10 (C) and (D). Comparing SEM images of modified and non-modified samples under the same magnification, (Fig. 10 (B) and (C) with 10,000x), the modified sample shows a much finer and more uniform 
morphology. Under higher magnifications (50,000x, Fig. 10 (D)), the SEM images of the modified Pt particles prepared via modified electroplating show flower-like structures consisting of nanosized and loosely packed Pt flakes. Microscopically, such geometry provides a larger surface area than that of solid and smooth particles. This structure increases the contact area for ions in electrolytes and enhances the electrode performance. This unique crystalline structure, along with the uniform distribution, may explain why modified electrodeposition can generate higher performance $\mathrm{Pt} / \mathrm{C}$ electrodes.

\subsection{Possible Mechanisms of Pt Particle Aggregation on a Carbon Surface}

Like all other crystallization processes, electrochemical deposition of Pt metal particles can be separated into two major steps: formation of Pt nuclei and the growth of these nuclei. The morphology of Pt electrocatalysts is determined by the number of nuclei formed and the rate at which they grow. The number of Pt nuclei formed on a carbon support is determined by the uniformity and hydrophilicity of the carbon surface. Microscopically, some locations on the carbon electrode surface are favorable for the formation of Pt nuclei with easier access of electrons and electrolyte, while others are not. For example, during an electroplating process, peak locations on the carbon surface have higher current density (charge concentration effect) than do valley positions. Therefore, more Pt nuclei may be formed on peak (high) locations than in low positions. The growth of Pt nuclei at peak positions is also faster than the growth of those formed in the lower positions.

During pulsating electroplating the growth of Pt nuclei is favored based on the already existing nuclei The formation of new nuclei is more difficult than the particle growth on existing nuclei because less activation energy is needed for the growth. The mechanism of fast growth and fewer nuclei on an untreated carbon surface leads to larger Pt particle sizes and non-uniform morphology (Pt particle aggregation). This inherent drawback of pulsation electroplating explains the need for a higher number of electroplating cycles to achieve the higher performance level of prepared electrocatalysts (Fig. 2). When a carbon electrode is pre-deposited with a large number of Pt nanoparticle nuclei, especially with single $\mathrm{Pt}$ atoms, the growth of Pt particles during electroplating can start more easily on these existing nuclei (seeds). Because of the uniform distribution of the Pt seeds (free Pt atoms and nanosized particles) on the carbon surface, the morphology of the electroplated electrodes is more uniform and the Pt particles are finer. Therefore only a limited number of plating cycles is required to prepare higher performance electrodes, leading finally to the reduction of Pt loading. Fig. 11 schematically depicts the mechanisms of the morphologies of electroplating on modified and non-modified electrodes. 


\section{Conclusions}

Pulse electroplating on Pt nanoparticle seeded carbon electrodes has demonstrated enhanced ORR performance in comparison with that of commercial $\mathrm{Pt} / \mathrm{C}$ electrodes and non-modified $\mathrm{Pt} / \mathrm{C}$ electrodes. Both morphology and catalyst polarization performances have indicated that modified pulsation electrodeposition is an effective technology that can be used for the preparation of low Pt loading and high performance electrocatalysts for hydrogen PEM fuel cell applications. Fewer than 100 electroplating cycles, corresponding to less than about $0.1 \mathrm{mg} / \mathrm{cm}^{2} \mathrm{Pt}$ loading density, are needed to achieve catalyst performance significantly greater than that of a commercial Pt/C catalyst with Pt loading $0.5 \mathrm{mg} / \mathrm{cm}^{2}$ in the entire cell current density range. In comparison, over 500 plating cycles are required for non-modified carbon electrodes to achieve the ORR performance of the $\mathrm{Pt} / \mathrm{C}$ commercial catalyst in the lower current density range. In the higher current density range, non-modified samples cannot surpass the performance of a commercial catalyst. Atomic level analyses have revealed that single Pt atoms around Pt colloidal nanoparticles form atomic clusters that can serve as seeding nuclei for Pt pulse electrodeposition. Higher numbers of pre-deposited Pt free atoms and nanoparticles promote finer morphology and lead to enhanced performances of electrodes. The electrode performance results in this conceptual research were based on the rotating disk electrode method. Large scale full hydrogen PEM fuel cell experiments are needed to verify these findings. The optimization of the Pt nanoparticle seeding process requires detailed research efforts and the technology may potentially be used for large scale commercial applications for both hydrogen PEM fuel cells and water electrolysis cells.

\section{Acknowledgments}

The Authors of this paper acknowledge financial support from the US DOE via the DOE/FHI project. The assistance and support of Dr. David L. Block of the Florida Solar Energy Center is appreciated. Drs. Ke Han and Yan Xin of the National High Field Magnetic Laboratory, Florida State University, carried out atomic level STEM and are appreciated. 


\section{References}

[1]. H. Tsuchiya and O. Kobayashi, Int. J. Hydrogen Energy, 2004, 29, 985;

[2]. M.K. Debe, Nature, 2012, 486, 43;

[3]. Z. Chen, D. Higgins, A. Yu, L. Zhang and J.J. Zhang, Energy Environ. Sci., 2011,4, 3167;

[4]. M.M.E. Duarte, A.S. Pilla, J.M. Sieben, and C.E. Mayer, Electrochem. Comm., 2006, 8, 159;

[5]. H.Y. Cheh, J. Electrochem. Soc. 1971, 118, 1132;

[6]. N. Ibl, Surf. Technol., 1980, 10, 81;

[7]. Z.D. Wei, Y.C. Feng, L. Li, M.J. Liao, Y. Fu, C.X. Sun, Z.G. Shao, and P.K. Shen, J. Power Sources, 2008, 180, 84;

[8]. H. Kim, N. Subramanian, and B.N. Popov, J. Power Sources, 2004, 138, 14A;

[9]. S.M. Ayyadurai,Y.-Seok. Choi, P. Ganesan, S.P. Kumaraguru, and B.N. Popov, J.Electrochem. Soc., 2007, 154(10), B1063.

[10]. Cao, M., Wu, D., and Cao, R., CHEMCATCHEM, 2014, 6, 26-45. 
Table 1 Maximum Cell Power Densities of Modified and Non-Modified Carbon Electrodes

\begin{tabular}{lrccc}
\hline $\begin{array}{c}\text { Pt/C } \\
\text { Electrode }\end{array}$ & $\begin{array}{c}\text { Number } \\
\text { of } \\
\text { Plating } \\
\text { Cycles }\end{array}$ & $\begin{array}{c}\text { Maximum } \\
\text { Cell } \\
\text { Power } \\
\text { Density } \\
\left.\text { (mW/cm }{ }^{2}\right)\end{array}$ & $\begin{array}{c}\text { Cell } \\
\text { Voltage[a] }\end{array}$ & $\begin{array}{c}\text { Cell } \\
\text { Current } \\
\text { Density } \\
\left(\mathrm{mA} / \mathrm{cm}^{2}\right)\end{array}$ \\
\hline $\begin{array}{l}\text { Commercial } \\
\text { Pt/C }\end{array}$ & 0 & 12.79 & 0.474 & 27.00 \\
Non- & 0 & 5.34 & 0.500 & 10.69 \\
Modified & 100 & 12.36 & 0.446 & 27.72 \\
Pt/C & 300 & 13.57 & 0.550 & 24.67 \\
& 500 & 14.14 & 0.550 & 25.71 \\
& 0 & 6.84 & 0.400 & 17.11 \\
Modified & 50 & 12.19 & 0.501 & 24.34 \\
Pt/C (5X) & 100 & 13.61 & 0.500 & 27.21 \\
& 200 & 15.29 & 0.500 & 30.57 \\
Modified & 300 & 16.17 & 0.500 & 32.34 \\
Pt/C (8X) & 0 & 7.64 & 0.400 & 19.11 \\
& 50 & 12.13 & 0.450 & 26.96 \\
& 100 & 15.07 & 0.500 & 30.14 \\
\hline
\end{tabular}

[a] Corresponds to the Maximum power density. 


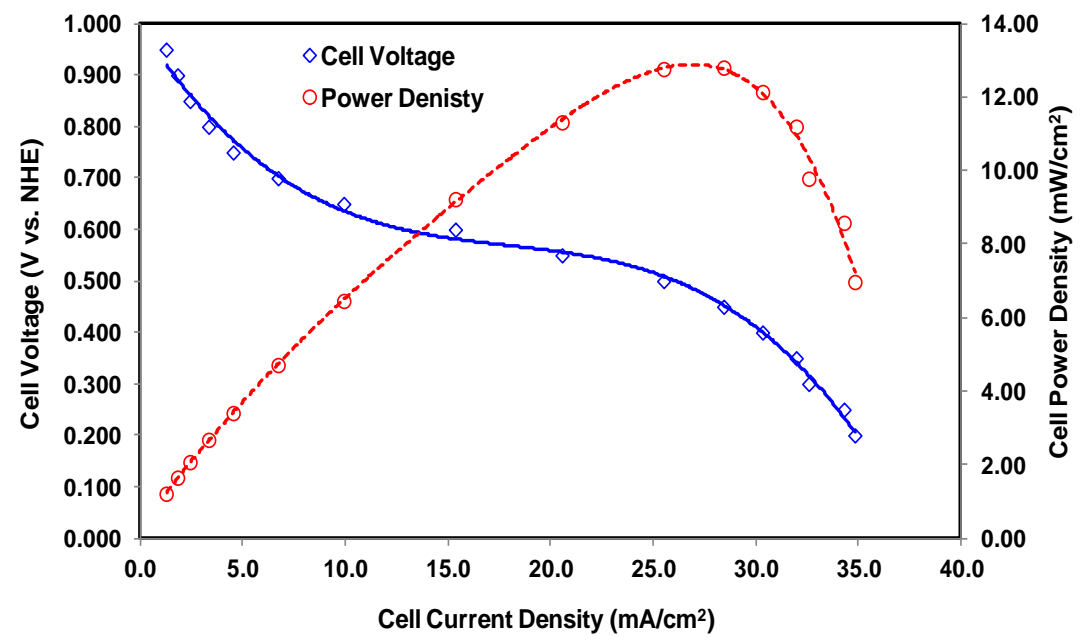

Figure 1. ORR polarization and cell power density of a commercial $\mathrm{Pt} / \mathrm{C}$ electrode.

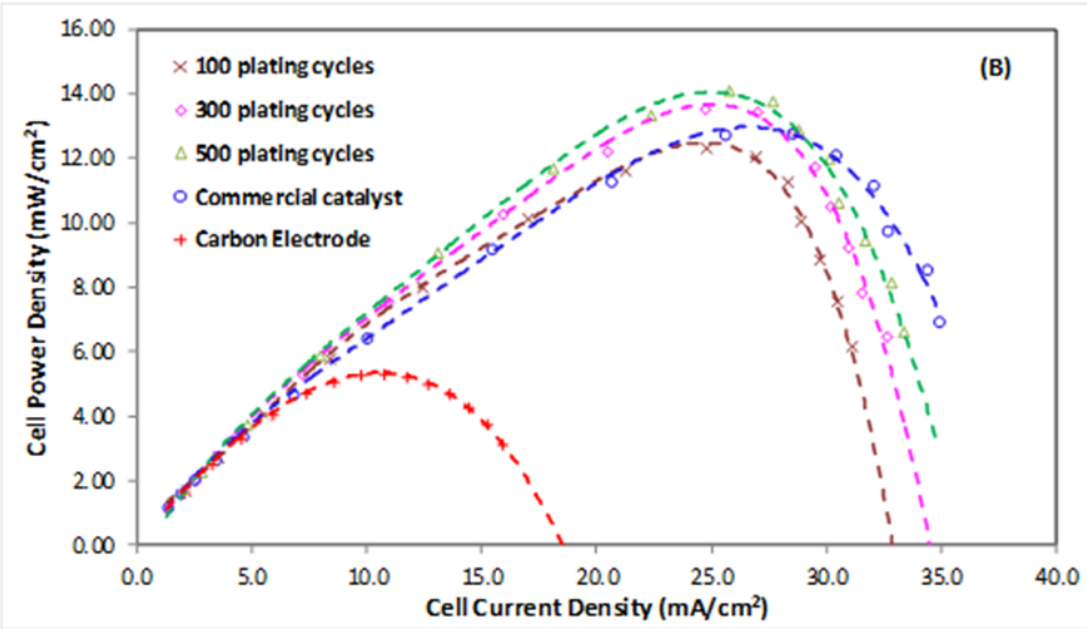

Figure 2. Power density of electroplating on non-modified Pt/C electrodes. 


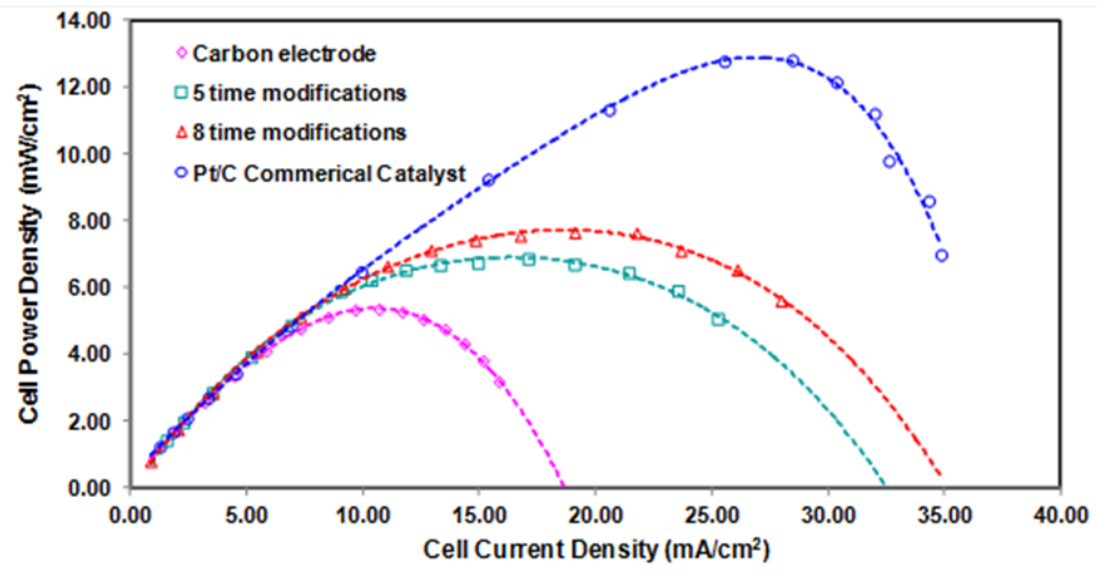

Figure 3. Cell power densities of Pt particle modified carbon electrodes.

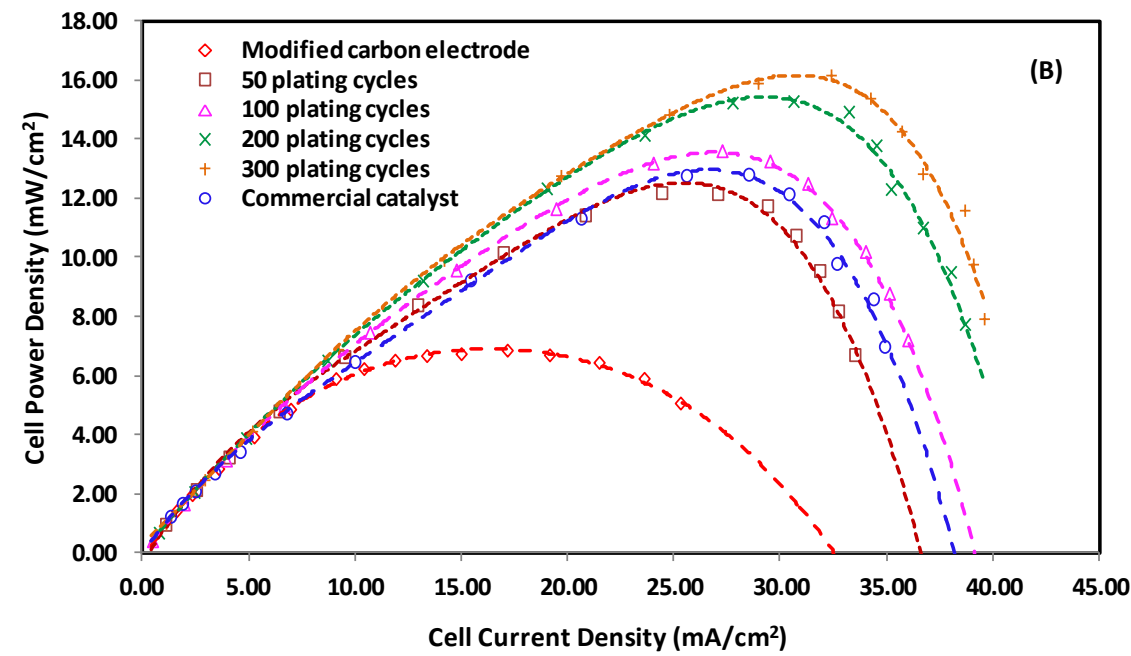

Figure 4. Cell power density of modified Pt/C (5 modifications) 


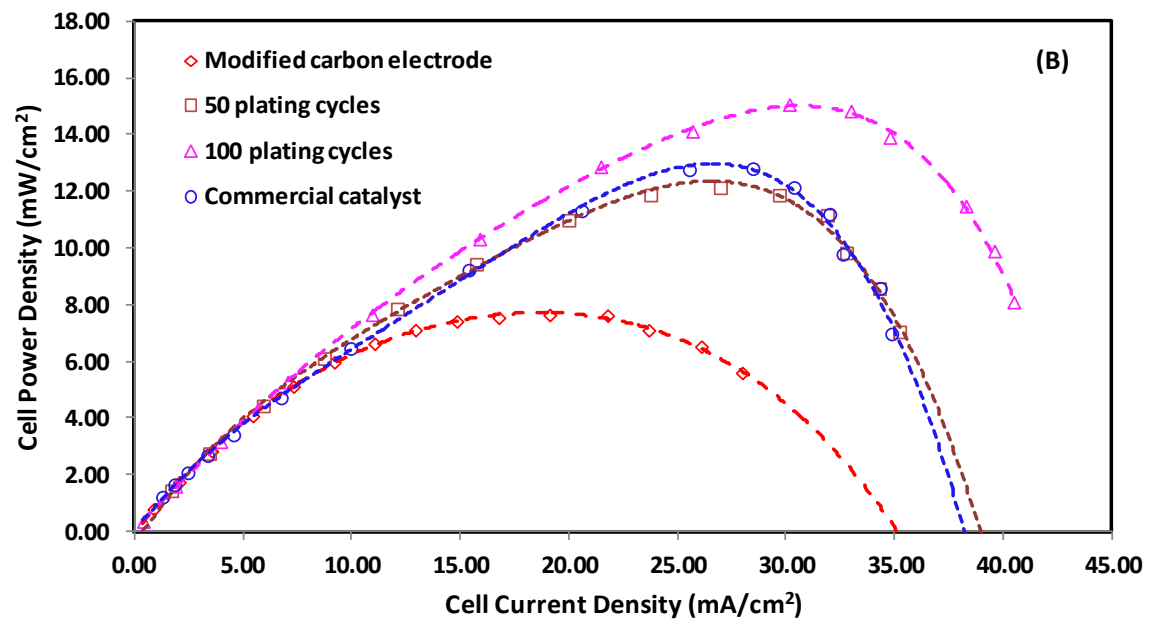

Figure 5. Cell power density of modified Pt/C (8 modifications)
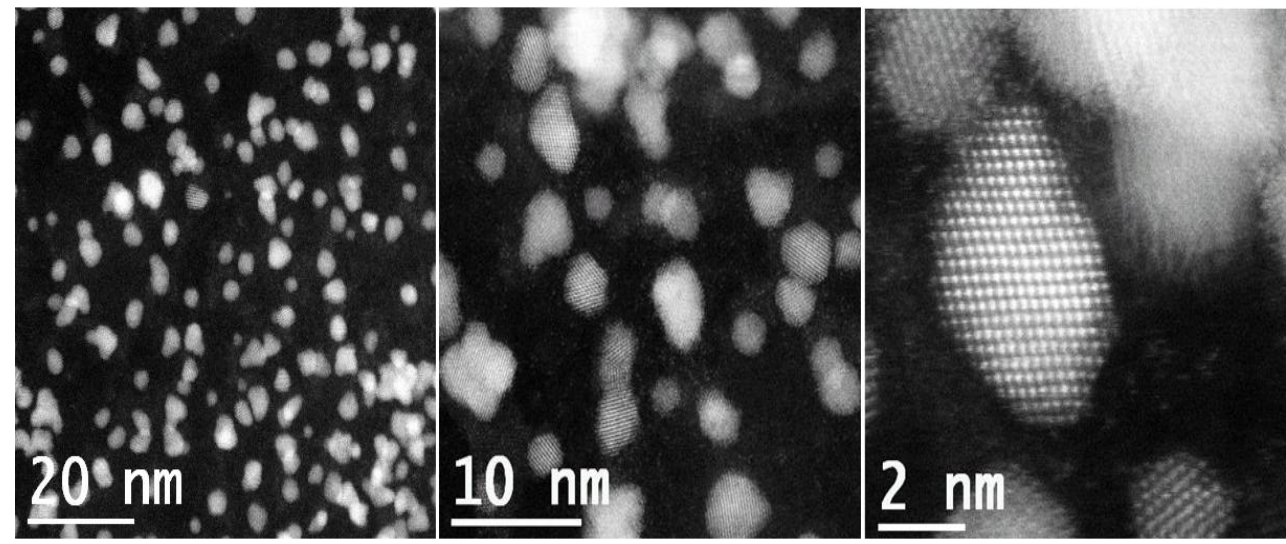

Figure 6. Atomic level analyses of nanosized Pt colloidal particles serving as $\mathrm{Pt}$ nuclei for modification of carbon electrodes. 

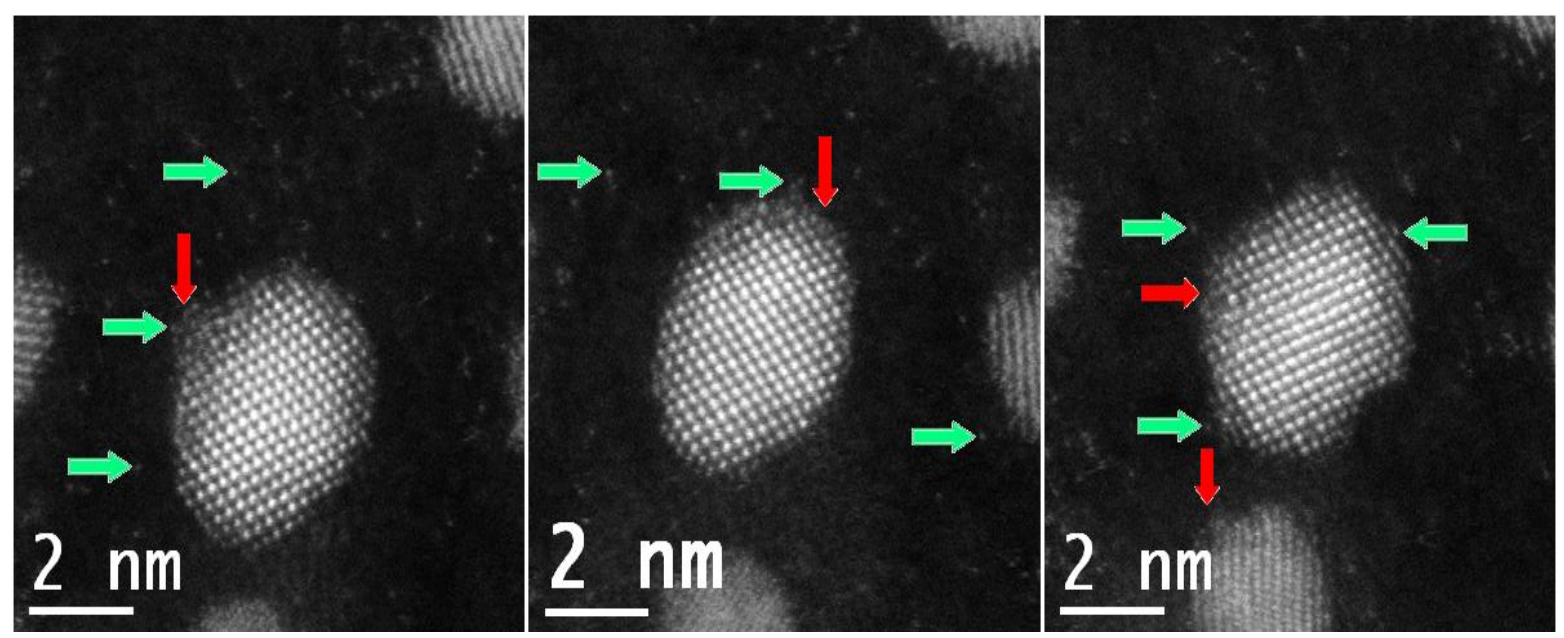

Figure 7. Atomic level analyses of a nanosized Pt particle. Green arrows point to single Pt atoms around a particle or among particles, and red arrows point to the non-crystalline areas. The particle is found rotating under electron beam radiation. From left to right, the same particle is exposed to an electron beam with $\mathrm{t}=0.0 \mathrm{sec}, 1.0 \mathrm{sec}$ and $2.0 \mathrm{sec}$.
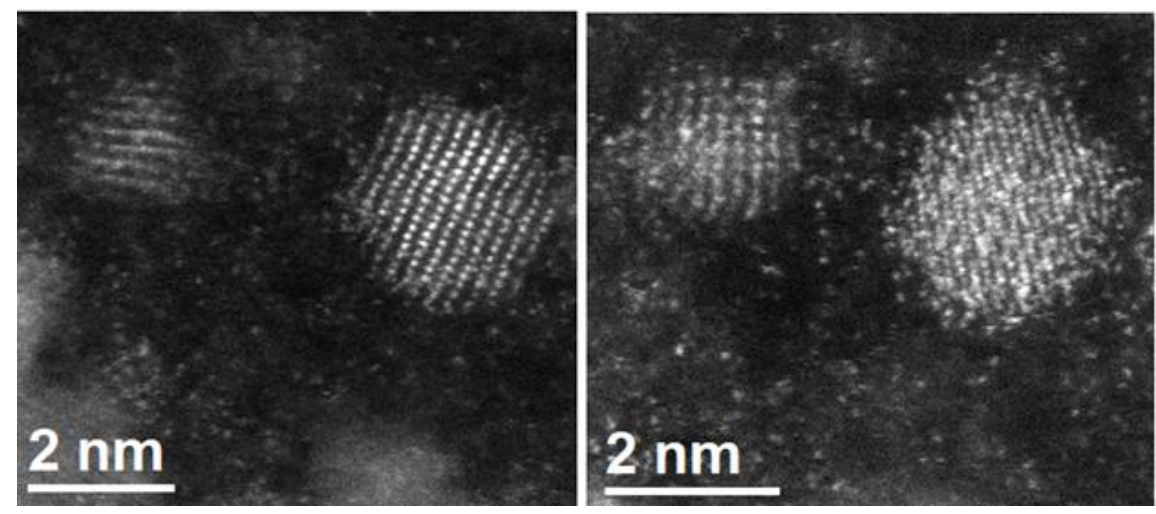

Figure 8. Pt particles not only underwent surface atom redistribution, but they also rotated to different orientations. Under bombardment by an electron beam during the STEM observation Pt particles started scattering and forming a large number of single Pt atoms around the original particles. This indicates that the prepared colloidal Pt particles are loosely packed, with undefined crystalline structures. 


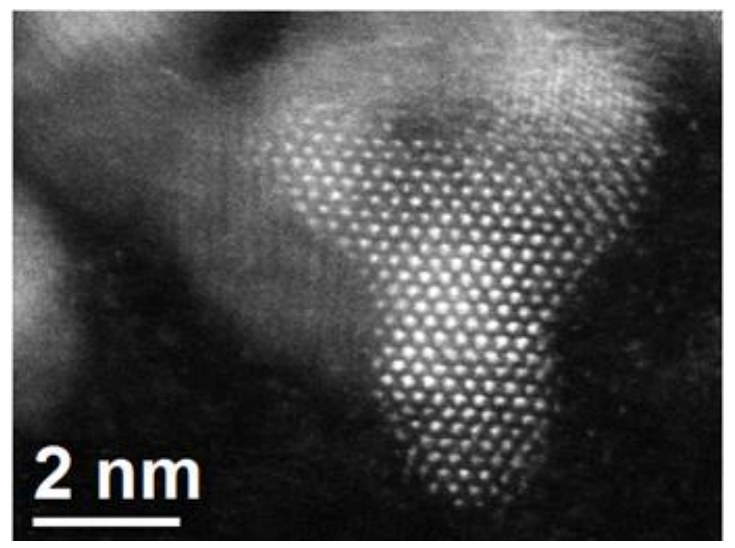

Figure 9. Aggregation of two Pt nanoparticles
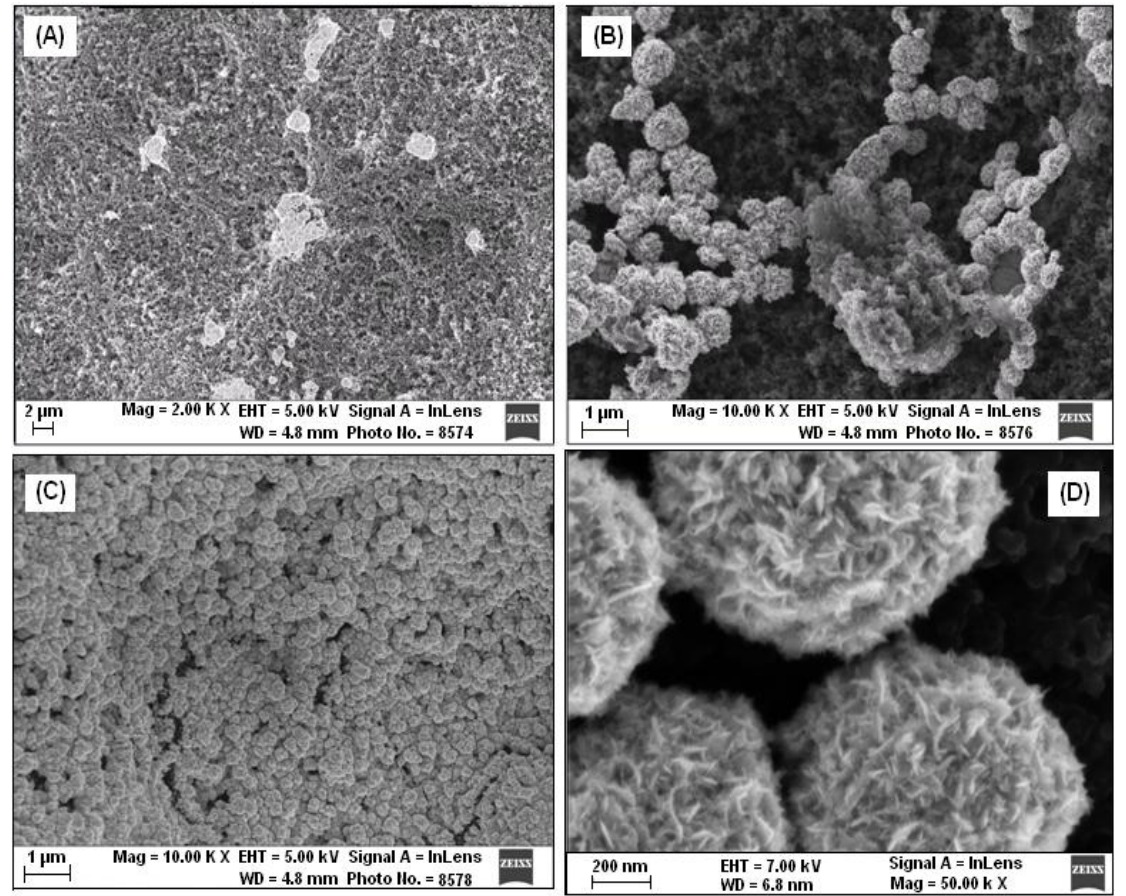

Figure 10. SEM images of electroplated electrodes (A): 500 electroplating cycles on a nonmodified carbon electrode, 2,000X magnification; (B): 300 electroplating cycles on a nonseeded carbon electrode, 10,000X magnification; (C) and (D): 300 electroplating cycles on a seeded carbon electrode, 50,000X magnification) 

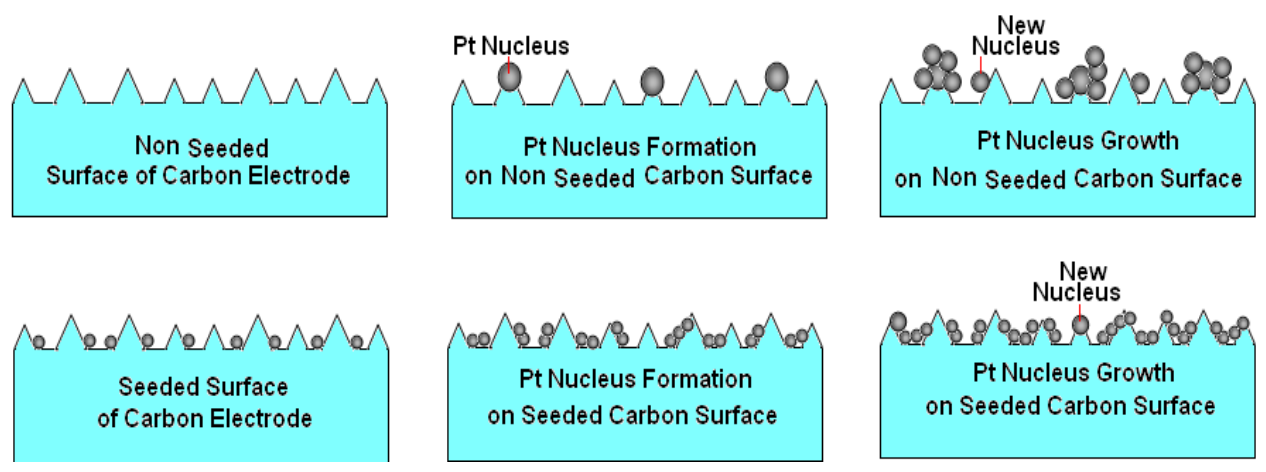

Figure 11. Pt nanoparticle formation and growth on seeded and non-seeded surfaces of carbon electrodes during pulsating electroplating. 